Editorial

\title{
Biocatalysis: Chemical Biosynthesis
}

\author{
Agatha Bastida \\ Department Bio-organic Chemistry, Institute of General Organic Chemistry (IQOG), The Spanish National \\ Research (CSIC), c/Juan de la Cierva 3, E-28006 Madrid, Spain; agatha.bastida@csic.es
}

Received: 28 March 2020; Accepted: 31 March 2020; Published: 2 April 2020

Biocatalysis is very appealing for industry because it allows the synthesis of products that are not accessible by chemical synthesis, use of alternative raw materials, lower operating costs, low fixed cost infrastructure and improved eco-efficiency [1]. Chemical biosynthesis has emerged as a valuable tool in organic chemistry that provides straightforward and efficient alternatives to traditional chemical synthesis [2]. Advances in enzyme discovery, high-throughput screening and protein engineering have substantially expanded the available biocatalysts, and consequently, many more synthetic transformations are now possible. The chemo-, regio-, diastereo- and enantio-selectivity of biocatalysts are among the properties that render them superior to chemical catalysts [3,4]. Enzymes are biodegradable and easily replaced through inexpensive and environmentally benign fermentation processes. The minimal environmental and economic burden posed by enzymes is further diminished by the potential to engineer even more active variants than can be found in nature, to optimize expression efficiencies and fermentation yields, and to immobilize and reuse these powerful catalysts. Biocatalysis has been used widely to produce chiral pharmaceutical intermediates to make small molecule drugs [5].

This Special Issue discusses some of the key drivers and scientific developments that are expanding the application of biocatalysis in the pharmaceutical industry through several examples; kinetic characteristics of cofactor-enzyme complex against aldehydes giving important pharmaceutical precursors [6], cyclodextrin glucanotransferase from Thermoanaerobacter $s p$ is able to glycosylate a ternary alchols [7,8], bi-enzymatic cascade for the synthesis of optically pure compounds [9], Sporomusa ovata used as microbial catalyst to determine whether electron uptake is hydrogen-dependent [10] and esterification of ferulate with octanol catalyzed by lipase in a solvent-free system [11]. In addition, two reviews on biocatalysis as a useful tool in asymmetric synthesis [12] and pseudokinases as suitable drug targets for the treatment of various diseases [13] give an idea about the impact of biocatalysis in drug development.

The research article of Karanam et al. deals with the importance of an (R) specific carbonyl reductase from Candida parapsilosis as a biocatalyst in the reduction of ketones and keto-esters of aliphatic and aromatic aldehydes [6]. García-Arellano et al. investigated the enzymatic synthesis, using a cyclodextrin glycosyltransferase from Thermoanaerobacter $s p$, of novel alkyl glycoside derivatives which are used as non-ionic surface-active agents in food, cosmetic and detergent industries [7]. Chiang et al. studied the enzymatic synthesis of new isoflavone glucosides, 8 -OHDe-7/8-O- $\beta$-glucoside, increasing its solubility and stability to be used in pharmaceutical and cosmeceutical applications [8]. The other paper in this Special Issue focuses on a particular application in the use of enzymatic cascades in one pot for the synthesis of active cyanohydrins [9]. Leemans et al. attempted to couple the hydrocynation of 4-anisaldehyde with the acetylation of the formed mandelonitrile catalyzed by Manihot esculenta hydroxynitrile lyase (an S-selective enzyme) and Candida antartica lipase A. Tremblay et al. used Sporomus ovata as the microbial catalyst to determine whether electron uptake is hydrogen dependent. Hydrogen was detected at $-500 \mathrm{mV}$ versus $\mathrm{Ag} / \mathrm{AgCl}$ by a micro-sensor in proximity to the cathode in a sterile fresh medium. As well, nickel and cobalt were detected at the cathode surface after 
exposure to the medium increasing the presence of $\mathrm{H}_{2}$. So, at least a part of the electrons coming from the electrode are transferred to the bacteria via hydrogen during microbial electrolysis [10]. Huang et al. described the enzymatic esterification of ferulic acid with octanol producing octyl ferulate in a high-temperature solvent-free system with an environmentally friendly method. Due to the limited solubility of ferulic acid in a lipophilic medium, the ester form of ferulic acid has better antioxidant and ultraviolet-absorbing activity [11].

We have two review papers in this Special Issue, one by Domínguez de María et al., presenting an excellent overview of recent progress on the assessment of granted patents about biocatalysis as a useful tool in asymmetric synthesis [12]. A vast area of enzyme is used and is performed by industry or academic groups. Around 200 granted patents have been identified, covering all enzyme types. The inventive pattern focuses on the protection of novel protein sequences, as well as on new substrates. In some other cases, combined processes, multi-step enzymatic reactions, as well as process conditions are the innovative basis. The most relevant found in this review was the protection of novel protein sequences for well-known reactions and the use of novel substrates for useful synthetic reactions. Biocatalysis is taking significant steps in chemical industries, being seriously considered as a powerful alternative for combining sustainable chemistry with high efficiency and selectivity.

A second review, by Jonathan Lees et al., deals with a class of pseudokinases enzymes and their potential as suitable drug targets for the treatment of various diseases, including metabolic, neurological, autoimmune, and cell proliferation disorders [13]. Pseudokinases are a subset of the protein kinase superfamily that present inactivating mutations in critical catalytic motifs, but signal primarily through non-catalytic mechanisms. These proteins play central roles in the cell, and the loss of their regulation can lead to a variety of diseases. Indeed, pseudokinase malfunctions occur in diverse diseases and represent a new therapeutic window for the development of innovative therapeutic approaches. Several clinically approved kinase inhibitors have been shown to influence the non-catalytic functions of active kinases, providing the expectation that similar properties in pseudokinases could be pharmacologically regulated. Recent advances in drug discovery, assisted by the use of artificial intelligence approaches, may pave the way for the rapid identification of potent pseudokinase inhibitors.

Thanks to all the authors for their valuable contributions and the editorial team of Catalysts for their kind support, without them, this Special Issue would not have been possible.

Conflicts of Interest: The authors declare no conflicts of interest.

\section{References}

1. Devine, P.N.; Howard, R.M.; Kumar, R.; Thompson, M.P.; Truppo, M.D.; Turner, N.J. Extending the application of biocatalysis to meet the challenges of drug development. Nat. Rev. Chem. 2018, 2, 409-421. [CrossRef]

2. Chouhan, S.; Sharma, K.; Zha, J.; Guleria, S.; Koffas Mattheos, A.G. Recent Advances in the Recombinant Biosynthesis of Polyphenols. Front Microbiol. 2017, 8, 2259. [CrossRef] [PubMed]

3. Martinez-Montero, L.; Schrittwieser, J.H.; Kroutil, W. Regioselective Biocatalytic Transformations Employing Transaminases and Tyrosine Phenol Lyases. Top. Catal. 2019, 62, 1208. [CrossRef]

4. Li, G.; Wang, J.B.; Reetz, M.T. Biocatalysts for the pharmaceutical industry created by structure-guided directed evolution of stereoselective enzymes. Bioorg. Med. Chem. 2017, 26, 1241-1251. [CrossRef] [PubMed]

5. Su, H.; Zhang, H.; Ang, E.L.; Zhao, H. Biocatalysis for the synthesis of pharmaceuticals and pharmaceutical intermediates. Bioorg. Med. Chem. 2018, 26, 1275-1284. [CrossRef]

6. Karanam, V.K.; Chaudhury, D.; Chadha, A. Understanding (R) Specific Carbonyl Reductase from Candida parapsilosis ATCC 7330 [CpCR]: Substrate Scope, Kinetic Studies and the Role of Zinc. Catalysts 2019, 9, 702. [CrossRef]

7. Garcia-Arellano, H.; Gonzalez-Alfonso, J.L.; Ubilla, C.; Comelles, F.; Alcalde, M.; Bernabé, M.; Parra, J.-L.; Ballesteros, A.O.; Plou, F.J. Production and Surfactant Properties of Tert-Butyl-D-Glucopyranosides Catalyzed by Cyclodextrin Glucanotransferase. Catalysts 2019, 9, 575. [CrossRef] 
8. Chiang, C.-M.; Wang, T.-Y.; Yang, S.-Y.; Wu, J.-Y.; Chang, T.-S. Production of New Isoflavone Glucosides from Glycosylation of 8-Hydroxydaidzein by Glycosyltransferase from Bacillus subtilis ATCC 6633. Catalysts 2018, 8, 387. [CrossRef]

9. Leemans, L.; Langen, L.V.; Hollmann, F.; Schallmey, A. Bi-enzymatic Cascade for the Synthesis of an Optically Active O-benzoyl Cyanohydrin. Catalysts 2019, 9, 522. [CrossRef]

10. Tremblay, P.-L.; Faraghiparapari, N.; Zhang, T. Accelerated $\mathrm{H}_{2}$ Evolution during Microbial Electrosynthesis with Sporomusa ovata. Catalysts 2019, 9, 166. [CrossRef]

11. Huang, S.-M.; Wu, P.-Y.; Chen, J.-H.; Kuo, C.-H.; Shieh, C.-J. Developing a High-Temperature Solvent-Free System for Efficient Biocatalysis of Octyl Ferulate. Catalysts 2018, 8, 338. [CrossRef]

12. Gonzalo de Gonzalo, P.D.; Alcántara, A.R. Biocatalysis as Useful Tool in Asymmetric Synthesis: An Assessment of Recently Granted Patents (2014-2019). Catalysts 2019, 9, 802. [CrossRef]

13. Jonathan Lees, A.T.; Santana, A.G.; Bolanos-Garcia, V.M.; Bastida, A. Pseudokinases: From Allosteric Regulation of Catalytic Domains and the Formation of Macromolecular Assemblies to Emerging Drug Targets. Catalysts 2019, 9, 778. [CrossRef]

(C) 2020 by the author. Licensee MDPI, Basel, Switzerland. This article is an open access article distributed under the terms and conditions of the Creative Commons Attribution (CC BY) license (http://creativecommons.org/licenses/by/4.0/). 